\title{
New Directions in L2 Lexical Development
}

\author{
Shigenori Tanaka \\ Keio University \\ doi: http://dx.doi.org/10.7820/vli.v01.1.tanaka
}

\begin{abstract}
Lexical competence can be defined as one's ability to use words differentially and fully. In this paper I shall first present my views concerning lexical development in order to comment on each of the following four articles: Lexical Development and Learners' Practices in a Content-based Learning Course by Andy Barfield; The Frequency Model of Vocabulary Learning and Japanese Learners by Dale Brown; A Study of Learners' Intuitions Behind the Use of Utterance Verbs in English by Yoshiaki Sato and Aaron Batty; and, Utilizing Student-Generated Pictures for Formative Vocabulary Instruction by Charles Anderson.
\end{abstract}

Keywords: lexical competence; lexical development; second language acquisition; vocabulary breadth; vocabulary depth; discussant; vocabulary symposium.

\section{Introduction}

The study of lexicon is too broad and complex and many-sided to fit easily into the standard academic divisions of "disciplines." Relevant fields include lexicography, etymology, corpus linguistics, cognitive linguistics, developmental psychology, cultural studies, language acquisition, and language teaching, just to name several representative domains. This vocabulary symposium is, however, primarily concerned with second language acquisition and second language teaching. The key questions to be addressed are as follows: How does a second language learner develop lexical competence in the target language? How does a language teacher facilitate the process of acquiring that competence?

In recent years, there have been an increasing number of both theoretical and empirical studies concerning how lexical competence develops in a second language learner, and under what conditions (for recent studies see Boggards \& Laufer, 2004; Daller, Milton, \& Treffers-Daller, 2007; David, 2008; Fitzpatrick, Al-Qarni, \& Meara, 2008; Hilton, 2008; Jiang, 2000; Laufer \& Hulstijn, 2001; Meara \& Fitzpatrick, 2000; Milton, 2008; Nation, 2007; Vermeer, 2001). However, it seems that researchers have yet to reach a consensus on the definition of lexical competence (i.e. the objective of learning vocabulary). Defining what we are after operationally is the crucial first step. Once operationally defined in a valid way, the concept of lexical competence becomes a guiding principle when designing empirical research on lexical acquisition, devising measures of vocabulary testing, and developing curriculum for teaching vocabulary. Without knowing what the target construct is, we cannot be on the right track when pursuing our research projects.

Regarding the question of what word knowledge is, Nation (2001) made a three-way distinction: knowledge of form (phonological and graphic forms), knowledge of meaning (form and meaning, concepts, referents, and associations), 
and knowledge of usage (grammatical functions, collocations, and constraints on use). This is nothing more than a list of elements constituting word knowledge, and yet the list conveys what to consider when dealing with this matter. Daller et al. (2007) characterize the complexity of lexical knowledge in terms of "breadth," "depth," and "fluency." Vocabulary breadth roughly means the number of words a learner knows, while vocabulary depth refers to the learner's knowledge about their usage. Fluency is a notion which explains how easily the learner can recognize and use those words.

It appears that useful concepts are on the table, and yet they have to be combined in an intuitively more appealing way to produce a useful definition. In my opinion, lexical competence can be defined as one's ability to use words differentially and fully. This definition suggests that lexical competence is a composite of interlexical competence (i.e. the ability to use words differentially) and intra-lexical competence (i.e. the ability to use a given word fully).

In addition, I would make an additional distinction between basic lexical competence and extended lexical competence. Basic lexical competence refers to one's ability to select the most appropriate basic or common word in context (inter-lexical competence), and to use a given basic word through its full range of usages (intralexical competence). For example, inter-lexical competence makes it possible for a learner to use "put" and "set" differentially. With intra-lexical competence, the learner is able to use "put" freely in different contexts such as "put some eye drops in one's eyes," "put a ladder against the wall," "put a stamp on the envelope," "put a 100 dollar bill in the envelope". In reality, we intuitively know that the learner's use of "put" is limited to certain exemplars, thus exhibiting the case of semantic under-extension.

Basic lexical competence should be a common foundation of the learner's lexical competence. In other words, basic lexical competence refers to the common lexis required to allow individuals to communicate effectively in the target language in common situations. Once established, the learner needs to develop his or her extended lexical competence in order to more deeply explore his/her particular interests and concerns. The learner expands his or her mental lexicon in terms of not only "thematic range," but also "vocabulary size." Thus we can expect that learners" extended lexical competence should differ according to each individual's hobbies and occupations.

Generally, lexical competence is one's ability to use words differentially and fully. More specifically, we have basic lexical competence and extended lexical competence. The meaning potential of basic words is normally much greater than that of extended words. Thus, the general definition above applies directly to basic lexical competence. Extended lexical competence, on the other hand, involves the number of both productive and receptive words. So you can say that in addition to the basic words, the learner knows 6000 words or 10,000 other words. However, vocabulary size alone does not suffice as a lexical indicator; thus, we add the concept of thematic range. Extended lexical competence should be naturally skewed towards to the learner's interests and needs; it is topic-oriented lexical competence. Essentially the important questions are: How many words does the learner have in his or her mental lexicon? and What is the topical coverage? or simply How many words in what topics?

As a discussant at this symposium, my role is to review and comment on the following four papers: Lexical Development and Learners' Practices in a 
Content-based Learning Course by Andy Barfield; The Frequency Model of Vocabulary Learning and Japanese Learners by Dale Brown; A Study of Learners' Intuitions Behind the Use of Utterance Verbs in English by Yoshiaki Sato and Aaron Batty; and, Utilizing Student-Generated Pictures for Formative Vocabulary Instruction by Charles Anderson.

\section{On Barfield's Paper}

Barfield is concerned with the relationship between lexical development and learner autonomy. This relationship is one of our most important pedagogical objectives; helping learners become independent, responsible, and autonomous in their attempts at learning a second language. "Learner autonomy" is a concept that captures this objective. When applied to lexical learning in English, as Barfield suggests, learners take on the task of learning vocabulary and try to develop their lexical competence on their own, and by trial and error finding their personal ways of learning. The assumption behind this idea is that there is a tremendous amount of individual variation with respect to how individuals learn a second language in general, and L2 vocabulary specifically. This is not limited to inter-individual variation, but it also applies to intra-individual variation. A learner's learning style is subject to developmental change as the learner grows in the target language.

Barfield provides an enlightening account of how learner autonomy fosters sound lexical acquisition. The adjective "sound" here can be replaced by "useful" or "communicative." It is possible that learners' lexicon remains simply knowledge, failing to become part of the learner's communicative competence. This brings up a situation where the learner knows a lot about English words, but cannot use them for communicative purposes. Barfield explains this gap in terms of "school knowledge" and "action knowledge," a distinction originally made by Barnes (2008). For instance, learners may learn English vocabulary in the same way as they learn Japanese history. Knowing does not guarantee the ability of usage.

Then, how does the learner develop action knowledge readily available for language use? Barfield agrees with Barnes' constructivist view of learning, and cites Little (2007) on "learner autonomy" to introduce the concepts of learner involvement, learner reflection, and appropriate target use. "Learner involvement" is a prerequisite of developing learner autonomy. It is a prerequisite of good learning in general. Obviously, one can acquire practical competence in language only by using it in an appropriate way. Thus, "appropriate target use" is also an essential condition for learner autonomy. The most difficult condition to satisfy is "learner reflection." Conceptually it is easy to understand what this is: the learner makes his or her own analysis and judgment about how he or she is doing. Involvement and language use are straightforward even in practice, but reflection is troublesome because a set of criteria is required for distinguishing "good reflection" from "poor reflection." It is not a matter of quantity, but a matter of quality.

Learner autonomy is a general concept in education. When it is applied to lexical development in particular, we need to show how learner autonomy in L2 lexical development is fostered. In this respect, Barfield seems to favor contentbased lexical development and points out that learner-generated materials, which 
are based on the learners' own interests and priorities, are more personal and thus meaningful in the sense of topic-based network building.

In the mental lexicon, words do not exist in isolation of other words; rather, they form lexical networks which can be easily triggered when a related topic is given. This is connected to the concept of extended lexical competence, discussed above.

Lexical restructuring is an interesting concept. Learner reflection should be a driving force for restructuring. Yet the nature of reflection still remains to be explored. Barfield (2012, p. 11) asks an interesting question, as shown below:

The pressure to cram vocabulary for university entrance exams in Japan is one example of how an overbearing emphasis on school knowledge forces learners into specific vocabulary practices that distance them from using the language meaningfully for their own purposes. How does this impact their later vocabulary practices and goals when they continue learning English beyond (high) school?

In other words, learners come to our university classrooms with crammedat-school knowledge about English vocabulary. Their knowledge may consist of a list of 6000 words, most likely in the form of a one-to-one correspondence between the English word and its Japanese counterpart. However, most words are not personalized. They are not semantically connected to each other to form lexical networks. They are not readily available as language resources for spontaneous use in communication. However, Japanese learners arrive in class with something; a list of English words which could be restructured into something personal, meaningful, and authentic.

Barfield is correct to suggest that content-based research can help bridge the gap between school knowledge and action knowledge, fostering lexical development linked with content knowledge construction.

\section{On Brown's Paper}

Brown is concerned with what he calls "the frequency model of vocabulary learning." The general claim is that students learn words in the order of their frequency of occurrence. Along with Ellis (2002), Brown claims that "frequency is recognized as a key driver of all aspects of language learning, and indeed of human learning in general."

This has an intuitive appeal. Few would argue against the idea that some words occur more often than others. The logic of the frequency model is this: the more one encounters certain words, the better one tends to learn them. In other words, exposure to words is a strong condition for lexical acquisition.

To use the frequency model empirically or in curriculum design, however, we need to have frequency information beforehand, so that we can rank words in the order of frequency. Frequency information is generally drawn from corpus data, and so suffers inevitably from sampling bias. A corpus of any magnitude cannot be the general model of the English language, which is a theoretical sum of possible English uses. 
Even the well-known British National Corpus (BNC) is, as Brown points out (along with Nation, 2004), "a corpus of British, adult, formal, informative language." Moreover, it is no more than a sample drawn from an ever-increasing population. English has become the "global language," which is spoken virtually all over the world for various practical purposes. The degree of diversity will easily intensify as the spread of English-speaking people widens.

In theory, no corpus can be representative of the ever-diversifying population. If the source corpus is biased, then the frequency of occurrence attached to each word loses its empirical validity. With this in mind, Brown suggests that Japanese learners of English can benefit more, if we use a corpus representative of the kinds of English they experience. He suggests that the JACET 8000 list can be a better source of information when applying the frequency model to Japanese learners.

Brown argues that frequency is an important measure in second language learning and teaching. It seems reasonable to assume that the most frequent words are also generally the most useful because those words enjoy wide coverage in any text. However, what matters is how we obtain reliable and valid frequency data and how we use this data in the practice of teaching English as a second language.

In order to use frequency data effectively, a distinction is needed between "domain-general lexicon" and "domain-specific lexicon." Domain-general lexicon refers to a set of common words irrespective of semantic fields or topics. The aforementioned basic words are at the center of this set. To a certain extent any corpus may be useful in that the high frequency words remain the same regardless of the corpus selected. In other words, there should be a stable common core of basic words irrespective of linguistic diversity.

In contrast, however, domain-specific words are subject to thematic ranges. Thus, English has a lexicon for cooking, finance, government, education, ecology, information technology, and the like. Thematic ranges differ according to one's interests and concerns. For example, some learners may be more interested in learning vocabulary related to climate and weather than cooking and education. In that case, they would be willing to learn words and phrases such as tropical zone, rain forest climate, monsoon climate, savanna climate, approaching disturbance, El Niño, La Niña, and so on.

Given this division of lexical domain, it may be possible to employ a general corpus for common words to obtain their frequency. However, for domain-specific words, a domain-specific corpora will be required. For that purpose, we need to have a theory which enables the handling of the huge domain of human activities, and then develop domain-specific databases or corpora. This is a formidable task, but surely one worth the challenge.

\section{On Sato and Batty's Paper}

Sato and Batty conducted an interesting study concerning Japanese learner's lexical intuitions about the use of four utterance verbs: "speak," "talk," "say," and "tell." A considerable number of studies have been reported with respect to the acquisition of intra-lexical competence. The most notable case is "break" as in the study by Kellerman (1977). However, few studies have been conducted in the area of 
the acquisition of inter-lexical competence. So I consider Sato and Batty's paper a pioneering study.

As Sato and Batty correctly claim, the aforementioned verbs are generally called "basic verbs" in English, and learners are likely to encounter them in the earliest stages of language learning. In fact, those four verbs are ranked among the top 100 in terms of the frequency of occurrence in the BNC. We naturally expect that learners all know these verbs and they tend to perceive them to be easy words to learn, as compared to, for example, "inform," "declare," "utter," and "proclaim".

As pointed out in relation to Barfield's study, knowing something does not guarantee the ability of using it. Sato and Batty, thus, asked Japanese university students of different English proficiency levels to participate in their empirical study. Sato and Batty had participants choose the most appropriate utterance verb, while completing a cloze (fill in the blank) sentence activity.

It turned out that Japanese students found it troublesome to use the target words fully and differentially. The results were basically consistent among the participants, irrespective of their levels of proficiency. Even returnees, who had spent several years in English-speaking countries, failed when using their intuitions about certain usages of "speak" and "talk." By contrast, native speakers of English gave uniform responses to almost all test items.

This study shows that the native speaker's intuitions are hard to develop by only having exposure to the target language. Returnees had been in an input-rich environment, and yet, they failed to match the native speakers' accuracy in the use of these semantically related basic verbs. This means that incidental learning has its limitations; the quantity and quality of language exposure and language use alone do not guarantee full-fledged linguistic competence in the target language.

"Speak" and "talk" sometimes behave alike. You can say either "I want to talk to you" or "I want to speak to you" to mean basically the same thing. However, you can talk without speaking as you can hear without listening. A gorilla can talk, but it can't speak. What does this differential use of "speak" and "talk" suggest? I think it suggests that the Bolingerian principles of "one form for one meaning" and "one meaning for one form" hold true when it comes to lexical semantics (Bolinger, 1977). In other words, "speak" and "talk" are different in form, and then, in principle, they should differ in meaning.

For example, we may ask: Why is it that "a nice speaking voice" as in "She has a nice speaking voice" is much more common than "a nice talking voice"? The explanation should rest on the semantics of "speak" and "talk." As Sato and Batty explain, the verb "speak" highlights the aspect of emitting language sounds, carrying a sense of "one-way" direction. Thus, we have expressions such as: "She has a nice speaking voice," "This painting really speaks a lot," "My parrot speaks in a loud voice," and "Actions speak louder than words." By contrast, "talk" is a verb that emphasizes two-way interaction. Thus, we have expressions such as: "We have a talk show tonight," "We talked a lot about the issue, but didn't come up with a good solution," "My baby began to talk at the age of 7 months," and "Money talks." Talking is the act of two-way interaction, which, in turn, implies "the negotiation of meaning" in the broadest sense of the term. Thus, we can say, "They are talking without speaking," when they are interacting with the use of sign language. The saying "Money talks" sounds right because "talk" implies some kind of negotiation 
between the parties and the expression implies that money has a negotiating power. The spontaneous expression "Money speaks" may sound bizarre in that money does not emit a linguistic sound.

As Sato and Batty correctly argue, syntactically marked expressions such as "talk business" and "talk religion" equally imply verbal interaction of some kind, and the use of the verb "talk" is motivated here. It must be noted, however, that "talk business" is not the paradigm case of the transitive use of "talk" - at least, the degree of transitivity is very low with the verb "talk" here. Likewise, business and religion are not topics per se, but rather, they probably indicate types of talk (i.e. business talk and religion talk). When business is topicalized in the form of "our business" or "a new business," then we need to use a preposition like "about" or "on" as in "Let's talk about our business." The main point here is that verbal interaction is associated with the verb "talk."

If mere exposure to the target language does not suffice to develop lexical intuitions, then Sato and Batty are correct when they claim that carefully designed pedagogical devices should be developed to help learners improve their lexical competence.

\section{On Anderson's Paper}

In Anderson's study, the key issue is whether the use of a picture-drawing technique helps students learn English vocabulary and in what way. Given words such as "true," quick," and "surprised," a Japanese student easily comes up with the translation equivalent for each target word. However, Anderson argues that when we ask students to draw pictures which may illustrate their interpreted meanings, we are giving them opportunities to personalize the word meaning, which, in turn, leads to deeper lexical understanding.

One of Anderson's points is that personalization has a pedagogical effect on vocabulary learning when the student's interpretation of the word meaning comes into play. In order to draw a picture of the word meaning, the student needs to interpret the meaning in his or her own way. Drawing a picture of the word meaning is a very personal experience. Additionally, personalization is the condition for meaningful learning. Once grasped in a personal way, the meaning is not simply public knowledge, but it becomes the learner's own personal knowledge.

Thus, drawing pictures becomes an effective learning strategy. Anderson further claims that it also becomes an effective pedagogical or teaching strategy when it is linked with feedback. Feedback can be a one-way direction from teacher to student. It can also be a two-way interaction between the teacher and the student, or even between students themselves. Intrinsically, feedback is both cognitive and affective; it is also either positive or negative in nature. Anderson uses the term "formative feedback," which is defined as feedback that drives the student to move forward in the pedagogical or real task he is engaged in. Formative feedback should be necessarily interactive and as it is a form of communication, the act of giving feedback necessitates giving unspoken messages; cognitive or affective and positive or negative. Anderson correctly points out that the student's pictures can become good foci for formative feedback. Some pictures are just apt and semantically transparent, and some are otherwise. Semantically opaque pictures motivate verbal 
interaction between the teacher and the student, through which the student modifies his or her ideas behind the picture in question. This is how the formative feedback session proceeds.

Overall, Anderson's paper is suggestive and instructive in terms of how the use of pictures or image schemas can be both an effective learning strategy and a teaching strategy. Here one comment should be added. Most common words are polysemous, having multiple senses. If such is the case, then a simple one-to-one correspondence between the word sense and the sense picture does not suffice. What is needed here is a theory of lexical semantics. For that purpose, we may be tempted to turn to the field of linguistics and choose what looks like the best-fitting theory among many. However, this temptation has to be resisted because linguistics does not take second language learning and teaching into consideration when they do their lexical studies. What we really need is a pedagogically sound theory of lexical semantics. On the basis of the findings of lexical acquisition research, we need to construct a theory of L2 lexical semantics with a cross-linguistic perspective.

\section{Conclusion}

In summary, imagery or pictures, frequency, learner autonomy, and lexical intuition are the key concepts explored in these four papers. Imagery is associated with effective lexical teaching when backed up by formative feedback. Frequency is a powerful indicator in determining what words should be introduced in which developmental stages. Learner autonomy requires a shift in teaching: the subordination of teaching to the promotion of learning. Lexical intuition should be the target of lexical teaching, with the pedagogical question being how teachers help learners develop their lexical intuition.

All in all, these papers address the question of who learns what in what ways. On the basis of the claims made by the authors, we could envision the following scenario: an autonomous learner responsibly takes on the task of developing lexical intuitions: a set of criteria for freely using high frequency basic words as well as topic-related words of personal relevance in a multimodal and network-building way. It may be true that each construct needs further elaboration, but the four papers discussed have enabled us to see the light at the end of the tunnel of lexical learning and teaching in a second language.

\section{References}

Barfield, A. (2012). Lexical development and learners' practices in a content-based learning course. Vocabulary Learning and Instruction, 1(1), 10-19. doi:10.7820/ vli.v01.1.barfield

Barnes, D. (2008). Exploratory talk for learning. In N. Mercer \& S. Hodgkinson (Eds.), Exploring talk in schools (pp. 1-15). London: Sage.

Boggards, P., \& Laufer, B. (Eds.). (2004). Vocabulary in a second language: Selection, acquisition and testing. Amsterdam: John Benjamins.

Bolinger, D. (1977). Meaning and form. London: Longman. 
Daller, H., Milton, J., \& Treffers-Daller, J. (Eds.). (2007). Modelling and assessing vocabulary knowledge. Cambridge: Cambridge University Press.

David, A. (2008). Vocabulary breadth in French L2 learners. Language Learning Journal, 36(2), 167-180. doi:10.1080/09571730802389991

Ellis, N. (2002). Frequency effects in language processing. Studies in Second Language Acquisition, 24(2), 143-188. doi:10.1017/S0272263102002024

Fitzpatrick, T., Al-Qarni, I., \& Meara, P. (2008). Intensive vocabulary learning: A case study. Language Learning Journal, 36(2), 239-248. doi:10.1080/ 09571730802390759

Hilton, H. (2008). The link between vocabulary knowledge and spoken L2 proficiency. Language Learning Journal, 36(2), 153-166. doi:10.1080/ 09571730802389983

Jiang, N. (2000). Lexical representation and development in a second language. Applied Linguistics, 21(1), 47-77. doi:10.1093/applin/21.1.47

Kellerman, E. (1977). Towards a characterization of the strategy of transfer in second language learning. Interlanguage Studies Bulletin, 2(1), 58-145.

Laufer, B., \& Hulstijn, J. (2001). Incidental vocabulary acquisition in a second language: The construct of task induced involvement. Applied Linguistics, 22(1), 1-26. doi:10.1093/applin/22.1.1

Little, D. (2007). Introduction: Reconstructing learner and teacher autonomy in language education. In A. Barfield \& S. Brown (Eds.), Reconstructing autonomy in language education: Inquiry and innovation (pp. 1-13).

Basingstoke: Palgrave.

Meara, P., \& Fitzpatrick, T. (2000). Lex30: An improved method for assessing productive vocabulary in an L2. System, 28(1), 19-30. doi:10.1016/S0346251X(99)00058-5

Milton, J. (2008). Vocabulary uptake from informal learning tasks. Language Learning Journal, 36(2), 227-238. doi:10.1080/09571730802390742

Nation, I.S.P. (2001). Learning vocabulary in another language. Cambridge: Cambridge University Press.

Nation, I.S.P. (2004). A study of the most frequent word families in the British National Corpus. In P. Bogaards \& B. Laufer (Eds.), Vocabulary in a second language (pp. 3-13). Amsterdam: John Benjamins Publishing Company.

Nation, I.S.P. (2007). Fundamental issues in modelling and assessing vocabulary knowledge. In H. Daller, J. Milton \& J. Treffers-Daller (Eds.), Modelling and assessing vocabulary knowledge (pp. 33-43). Cambridge: Cambridge University Press.

Vermeer, A. (2001). Breadth and depth of vocabulary in relation to L1/L2 acquisition and frequency of input. Applied Psycholinguistics, 22(2), 217-234. doi:10.1017/S0142716401002041 